\title{
Physical stability and biological activity of biofilms under turbulent flow and low substrate concentration
}

\author{
L.F. Melo, M.J. Vieira
}

\begin{abstract}
The paper focuses on biofilms subject to turbulent flow and high liquid velocity (of the order of $1 \mathrm{~m} \mathrm{~s}^{-1}$ ) which can be found in heat exchangers, water distribution systems and in some wastewater reactors. An overall model describing biofilm development is presented, which includes the effects of biomass detachment due to the hydrodynamic forces. A methodology for estimating substrate consumption from data obtained through continuous monitoring of biofilm growth is presented. Results show that the physical stability of the biofilm increases with the liquid velocity, while the rate of substrate consumption decreases.
\end{abstract}

\begin{tabular}{ll}
\multicolumn{3}{l}{ List of symbols } \\
$1 / b$ & $(\mathrm{~s})$ \\
$J_{\mathrm{p}}$ & $\left(\mathrm{kg}_{\text {biofilm }} / \mathrm{m}^{2} \mathrm{~s}\right)$ \\
$J_{\mathrm{r}}$ & $\left(\mathrm{kg}_{\text {biofilm }} / \mathrm{m}^{2} \mathrm{~s}\right)$ \\
$K_{\mathrm{p}}$ & $\left(\mathrm{W} \mathrm{\textrm {m } ^ { - 1 }} \mathrm{K}^{-1}\right)$ \\
$K_{\mathrm{f}}$ & $\left(\mathrm{W} \mathrm{m}^{-1} \mathrm{~K}^{-1}\right)$ \\
$m_{\mathrm{f}}$ & $\left(\mathrm{kg}_{\text {biofilm }} / \mathrm{m}^{2}{ }_{\text {biofilm }}\right)$ \\
$m_{\mathrm{f}}^{*}$ & $\left(\mathrm{~kg}_{\text {biofilm }} / \mathrm{m}^{2}{ }_{\text {biofilm }}\right)$ \\
$m_{\mathrm{fa}}$ & $\left(\mathrm{kg}_{\text {active layer }} / \mathrm{m}^{2}{ }_{\text {biofilm }}\right)$ \\
$R_{\mathrm{f}}$ & $\left(\mathrm{m}^{2} \mathrm{~K} \mathrm{~W}^{-1}\right)$ \\
$t$ & $(\mathrm{~s})$ \\
$T_{1}$ & $(\mathrm{~K})$ \\
$T_{2}$ & $(\mathrm{~K})$
\end{tabular}

mechanical strength of the biofilm

biofilm production flux biofilm detachment or removal flux

thermal conductivity of the perspex wall

thermal conductivity of the biofilm

mass of biofilm per unit surface area

maximum mass of biofilm per unit surface area

mass of active layer per unit surface area

thermal resistance of the biofilm

time

temperature of thermocouple 1 temperature of thermocouple 2

Received: 5 May 1998

L.F. Melo, M.J. Vieira

University of Minho, Centro de Engenharia Biologica

Institute for Biotechnology and Fine Chemistry,

4700 Braga, Portugal

Correspondence to: L.F. Melo

The financial support of Programme PRAXIS XXI, through Contract no. 2.1/BIO/37/94 and of Programme INTERREG, through Contract no. 01/REG II/6/96 is gratefully acknowledged.
$T_{3} \quad(\mathrm{~K})$

$U \quad\left(\mathrm{~W} \mathrm{~m}^{-2} \mathrm{~K}^{-1}\right)$

$Y_{X / S} \quad\left(\mathrm{~kg}_{\text {biomass }} / \mathrm{kg}_{\text {substrate }}\right)$

Greek symbols

$\left(\mu_{\mathrm{p}} \quad\right.$ (kgiofilm produced $/$ $\mathrm{kg}_{\text {biofilm on the surface }} \mathrm{s}$ )

$\left(\mu_{\mathrm{p}}\right)_{\mathrm{a}} \quad\left(\mathrm{kg}_{\mathrm{biofilm}}\right.$ produced $/$ $\mathrm{kg}_{\text {biofilm on the surface }} \mathrm{s}$ )

$\rho_{\mathrm{f}} \quad\left(\right.$ dry $\mathrm{kg}_{\text {biofilm }} / \mathrm{m}^{3}$ biofilm $)$

$\rho_{\mathrm{f}} \quad$ (wet $\mathrm{kg}_{\text {biofilm }} / \mathrm{m}^{3}$ biofilm $)$

temperature of thermocouple 3 overall heat transfer coefficient biomass yield

biofilm specific production rate

biofilm specific production rate of the active layer

dry density of the biofilm (dry mass per unit volume) wet density of the biofilm

1

\section{Introduction}

A biofilm is a highly hydrated biological structure attached to a support, composed of micro-organisms, extra cellular polymeric substances produced by them, as well as abiotic particles captured from the liquid medium and incorporated in the film. The characteristics of such a structure depend not only on the microbial species involved and on the chemical composition of the fluid that is in contact with the biofilm, but also on the hydrodynamic conditions under which the biological layer is formed.

Much of the literature published so far on biofilm properties, activity and modeling is focused on microbial films formed under the operating conditions prevailing in most waste water treatment bioreactors: low or very low liquid velocities (of the order of 0.1 to $50 \mathrm{~m} \mathrm{~h}^{-1}$ ) and medium to high substrate concentrations, particularly in heterotrophic systems $[10,4,8]$. However, unwanted biofilms formed in contact with water circulating at much higher velocities (of the order of 0.1 to $3 \mathrm{~m} \mathrm{~s}^{-1}$ ) and turbulent flow, usually containing low organic substrate concentrations, are also quite important in many practical situations, such as in heat exchangers [3] and in drinking water distribution systems [18]. This so called "biofouling" phenomenon affects fluid flow and heat transfer efficiency, as well as public health and equipment maintenance. Moreover, it indirectly causes environmental problems due to the addition of biocides to the water in order to prevent or reduce biofouling in industrial equipment.

The effects of high liquid velocities on biofilm systems have been reported in the last 20 years $[1,6,20,15]$. Some authors advocate the use of high liquid velocities in bio- 
film reactors, since such biofilms are usually thinner, favouring the complete penetration of the substrate and reducing biomass wash-out $[19,5]$. Moreover, the current trend for water re-utilisation will undoubtedly emphasize the need for treating liquid streams with very low substrate concentrations which will probably result in the formation of thinner biofilms in the reactors. However, the relationships between operating conditions, biofilm thickness and substrate consumption are not yet quite clear: Peyton [14] found that the thickness of a Pseudomonas aeruginosa biofilm in a rotating annular reactor increased with increasing glucose loading rates; nevertheless, the thickness was not significantly affected by changes in the shear stress in the reactor. Tavares et al. [17] studied the effect of gas velocity on the growth of a heterotrophic biofilm in an aerobic three-phase fluidized bed reactor: the authors concluded that higher gas velocities resulted in thinner biofilms, although they did not seem to affect COD (Chemical Oxygen Demand) removal.

The substrate consumption by biofilms subject to low liquid velocities can be easily calculated from measured inlet and outlet substrate concentrations through axial mass balances to the reactor. However, in the case of heat exchangers and water transport systems, where turbulent flow prevails, the on-line determination of the activity (and, consequently, the modeling) of biofilms cannot rely upon the measurement of those substrate concentrations, since the residence time in the equipment is too short (a few seconds, in the case of heat exchangers) and/or the substrate concentration is too low. For that purpose, an overall mathematical model is presented below that takes into account the specific aspects of biofilm formation in conditions similar to the ones just mentioned. The effect of the hydrodynamic forces on biofilm detachment is much more intense in such cases than in laminar flow situations and is included in the model. This simple model has to be applied to data describing the growth rate of biofilms and, therefore, it demands the continuous monitoring of biofilm accumulation from the beginning of the attachment process. The present paper shows how the measurement of biofilm growth rate, together with the use of this overall model, can yield important information on the properties and behaviour of the biofilm, namely on its biological activity and physical stability.

\section{2}

\section{Overall model for biofilm development}

Let $m_{\mathrm{f}}$ be the mass of attached biofilm per unit surface area, at a given time $t$. The change in $m_{\mathrm{f}}$ with time is the result of two contradictory phenomena: the production of biomass by the micro-organisms in the biofilm and the removal of attached biomass (biofilm detachment) caused by the hydrodynamic forces:

$\frac{\mathrm{d} m_{\mathrm{f}}}{\mathrm{d} t}=J_{\mathrm{p}}-J_{\mathrm{r}}$,

$J_{\mathrm{p}}$ - "biofilm production flux" (increase in biofilm mass per unit time and unit surface area, associated to the production of biomass - cells plus extracellular polymers - as the result of the microbial activity within the biofilm), $\mathrm{M} \mathrm{L}^{-2} \mathrm{t}^{-1}$.
$J_{\mathrm{r}}$ - "biofilm detachment or removal flux" (decrease in biofilm mass per unit time and per unit surface area, associated to the detachment of parts of the biological deposit caused by the fluid forces), $\mathrm{M} \mathrm{L}^{-2} \mathrm{t}^{-1}$.

The "biofilm detachment flux" is assumed to be proportional to the amount of biomass attached to the surface, since the probability of existing "weak zones" in a thick biofilm is higher than in a thinner one. Therefore:

$J_{\mathrm{r}}=b m_{\mathrm{f}}$

where $b$ is proportional to the hydrodynamic forces acting upon the biofilm surface and varies inversely with the cohesiveness of the biofilm (i.e., $1 / b$ represents the "mechanical strength" or the "resistance to detachment" of the biofilm).

As regards the "production flux" $\left(J_{\mathrm{p}}\right)$, the colonisation of the clean surface by bacteria coming from the fluid is an essential feature only in the first hours of biofilm formation. Experimental results have shown that the subsequent growth of the biolayer is mainly due to the activity of the micro-organisms located in the attached film and not to the transport of new bacteria from the liquid to the biofilm surface [2].

Due to this biological activity and to diffusional limitations, the substrate concentration may in some cases decrease down to zero within the biofilm before reaching the surface of the support. Thus, modeling of the "biofilm production flux" $\left(J_{\mathrm{p}}\right)$ must take into account two different situations (named below as $\mathrm{i}$ and ii) during the build up of the biofilm layer. A mono-species biofilm will be considered here.

i) Thick biofilm, partially penetrated by the substrate In this case, there is an "active layer" located in the outer part of the biofilm, and a "non-active" layer that occupies the inner part of the biofilm, close to the support. The latter contains microbial species with residual activity as regards the main substrate, plus polymeric substances and, possibly, other microbial species that do not use that substrate.

If the biofilm is partially penetrated, then the active layer will have a constant thickness equal to the maximum depth of substrate penetration. On the contrary, the thickness of the inner layer can increase with time due, for instance, to the production of polymeric material by the micro-organisms in the active layer, which will result in an overall increase of the total amount of attached biomass.

Let $\mu_{\mathrm{p}}$ be the "biofilm specific production rate", that is, the mass of biofilm produced by the active layer per unit time and per unit mass of total biofilm. Thus, at a given time $t$ :

$\mu_{\mathrm{p}}=\left(\mu_{\mathrm{p}}\right)_{\mathrm{a}} \frac{\left(m_{\mathrm{f}}\right)_{\mathrm{a}}}{m_{\mathrm{f}}}$,

where $\left(\mu_{\mathrm{p}}\right)_{\mathrm{a}}$ is the (constant) biomass specific production rate of the active zone, i.e., the mass of biofilm produced per unit time and per unit mass of active layer, and $\left(m_{\mathrm{f}}\right)_{\mathrm{a}}$ is the mass of active layer per unit surface area (constant with time). 
Therefore :

$J_{\mathrm{p}}=\mu_{\mathrm{p}} m_{\mathrm{f}}=\left(\mu_{\mathrm{p}}\right)_{\mathrm{a}}\left(m_{\mathrm{f}}\right)_{\mathrm{a}}=$ constant.

ii) Thin biofilm, completely penetrated by the substrate In this case, the biofilm is biologically active (as regards the main substrate) throughout its entire depth, i.e. :

$\mu_{\mathrm{p}}=\left(\mu_{\mathrm{p}}\right)_{\mathrm{a}}$.

The mass of this active layer increases with time as the biofilm builds up, until its thickness reaches the maximum penetration depth. From this point on, case i) applies. It should be stressed, however, that the number of microorganisms in the biofilm does not increase proportionally to the biofilm mass, because the result of their activity is not only the production of new microbial cells but also of extra cellular substances (biopolymers). The latter, although not biologically active, can be a major fraction of the biofilm mass. As a consequence, the rate of biomass produced per unit mass of biofilm will decrease with time, meaning that the specific activity (i.e., per unit mass) of the active layer will get lower as its mass builds up. Therefore, in a completely penetrated biofilm, it does not seem unreasonable to assume that $\mu_{\mathrm{p}}$ is inversely proportional to the mass of active layer at each instant of time:

$\mu_{\mathrm{p}}=\left(\mu_{\mathrm{p}}\right)_{\mathrm{a}} \sim \frac{1}{\left(m_{\mathrm{f}}\right)_{\mathrm{a}}}$.

Since all the biofilm is active $\left(m_{\mathrm{f}}=m_{\mathrm{fa}}\right)$, the following equation may be applied to case ii):

$J_{\mathrm{p}}=\left(\mu_{\mathrm{p}}\right)_{\mathrm{a}}\left(m_{\mathrm{f}}\right)_{\mathrm{a}}=$ constant.

In both cases, i) and ii), $J_{\mathrm{p}}$ is constant. Replacing $J_{\mathrm{r}}$ in Eq. (1) by Eq. (2):

$\frac{\mathrm{d} m_{\mathrm{f}}}{\mathrm{d} t}=J_{\mathrm{p}}-b m_{\mathrm{f}}$,

which, upon integration, results in the final equation of the overall model:

$m_{\mathrm{f}}=m_{\mathrm{f}}^{*}[1-\exp (-b t)]$.

where $m_{\mathrm{f}}^{*}=\left(J_{\mathrm{p}} / b\right)$ is the maximum mass of biofilm, at steady state. Graphically, Eq. (9) represents a curve that tends to an asymptotic value of $m_{\mathrm{f}}$ for $t=$ infinite.

$J_{\mathrm{p}}$ can be modeled in more detail by taking into account the rates of mass transfer and biological reaction within the biofilm, according to well known concepts of heterogeneous catalysis. This will be the subject of another paper which is focused on the study of concentration profiles and biofilm efficiency in terms of substrate consumption. In the present work, the overall model, Eq. (9), will be used to interpret the data related to the physical stability and the biological activity of biofilms formed in a lab-scale heat exchanger under different operating conditions.

\section{3}

\section{Materials and methods}

The build up of the biofilm was monitored by measuring its heat transfer resistance, which is a non-invasive technique that can be applied during continuous operation. The micro-organism used as a biofilm producer was
Pseudomonas fluorescens, a gram-negative bacteria which commonly appears in natural waters. The cells were grown aerobically in a continuous culture at $27^{\circ} \mathrm{C}$ and $\mathrm{pH} 7$, using glucose as the limiting substrate. The growth medium was composed of glucose $(0.5 \%)$, peptone $(0.25 \%)$ and yeast extract $(0.125 \%)$ in distilled water, sterilised at $120^{\circ} \mathrm{C}$. The microbial suspension was diluted in pre-filtered tap water in a mixing tank (volume $=12 \mathrm{l}$ ), at a dilution rate of $1.2 \mathrm{~h}^{-1}$, which was high enough to prevent planktonic growth. The final liquid (here called the "test fluid"), containing around $6.10^{7}$ cells $\mathrm{ml}^{-1}$ and $20 \mathrm{mg} \mathrm{l}^{-1}$ of glucose was pumped through the test sections where the biofilms were formed under different fluid velocities ranging between $0.34 \mathrm{~m} \mathrm{~s}^{-1}$ and $0.97 \mathrm{~m} \mathrm{~s}^{-1}$ (shear stresses between $3.4 \mathrm{~N} / \mathrm{m}^{2}$ and $9.7 \mathrm{~N} / \mathrm{m}^{2}$, and Reynolds numbers between 4200 and 12000 ). Glucose concentration was determined colorimetrically by means of a Sigma Diagnostics Enzymatic Glucose Determinations Kit.

Basically, the test sections were vertical heat exchangers at laboratorial scale, each one made of a $60 \mathrm{~cm}$ long semicircular duct (hydraulic diameter $=1.08 \mathrm{~cm}$ ) containing three measurement zones ( $\mathrm{A}, \mathrm{B}$ and $\mathrm{C}$ ) along its axis (Fig. 1). The deposition surface was an aluminium plate, having one face in contact with the "test fluid" and the other one in contact with the perspex wall of a duct of rectangular cross section. Heat was provided to the "test fluid" by water circulating at $60^{\circ} \mathrm{C}$ in this rectangular duct. A grease of high thermal conductivity was spread between the metal plate and the perspex wall in order to improve the thermal contact between them.

In each one of the three zones A, B and C, two thermocouples were inserted in the perspex wall adjacent to the aluminium plate and a third one immersed in the fluid, as shown in Fig. 1. Therefore, the transversal heat transfer flux at each point $(A, B, C)$ could be calculated from the temperature data, at any instant of time during biofilm formation.

It can be easily shown that the overall heat transfer coefficient (U) is given by:

$\mathrm{U}=\frac{K_{\mathrm{p}}\left(T_{1}-T_{2}\right)}{y_{\mathrm{p}}\left(T_{1}-T_{3}\right)}$,

where $K_{\mathrm{p}}\left(=0.19 \mathrm{~W} \mathrm{~m}^{-1} \mathrm{~K}^{-1}\right)$ is the thermal conductivity of the perspex wall where thermocouples 1 and 2 are

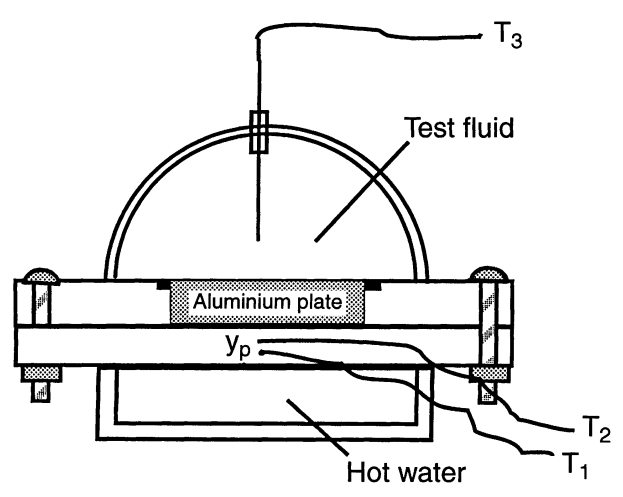

Fig. 1. Test section for continuous monitoring of biofilm development 
located, and $y_{\mathrm{p}}$ is the distance between these two thermocouples. The thermal resistance $\left(R_{\mathrm{f}}, \mathrm{m}^{2} \mathrm{~K} \mathrm{~W}^{-1}\right)$ introduced by the biofilm attached to the surface can be calculated from the values of the overall heat transfer coefficient at time $t=0$ (clean surface) and at any other time $t>0$. Changes in the convective heat transfer coefficient of the water caused by the increase in the surface roughness during biofilm development were taken into account in the calculation (see details in Vieira et al., [20]).

Since the water content of biofilms is often more than $90 \%(\mathrm{w} / \mathrm{w})$, the values of some of their physical properties, such as the wet density $\left(\rho_{\mathrm{f}}^{\prime}=1000 \mathrm{~kg} \mathrm{~m}^{-3}\right)$ and the thermal conductivity $\left(K_{\mathrm{f}}=0.6 \mathrm{~W} \mathrm{~m}^{-1} \mathrm{~K}^{-1}\right)$, can be considered similar to the ones of the water itself [7]. Therefore, the experimental results, here presented in mass units $\left(m_{\mathrm{f}}, \mathrm{kg}\right.$ of wet biofilm per $\mathrm{m}^{2}$ of surface area), were obtained from the correspondent values in thermal resistance units, by using the following relationshiping:

$m_{\mathrm{f}}=R_{\mathrm{f}} K_{\mathrm{f}} \rho_{\mathrm{f}}^{\prime}$,

where $R_{\mathrm{f}}$ is the thermal resistance introduced by the biofilm layer.

\section{4}

\section{Results and discussion}

Biofilm development is illustrated in Fig. 2 by three sets of data corresponding to the formation of microbial films in contact with a "test fluid" flowing at different velocities, containing the same substrate concentration (20 ppm): higher velocities result in smaller amounts of attached biomass, which also means lower thicknesses (Vieira et al., 1993). The data represents the average values measured in zones A, B and C. The overall model given by Eq. (9) (full lines in Fig. 2) fits well to these data. The average thickness of the biofilms formed in the tests varied between $1.290 \mathrm{~mm}$ (lower velocities) and $0.460 \mathrm{~mm}$ (higher velocities), at steady state.

To test the physical stability of the biological deposits, a change of the fluid velocity was imposed on two steadystate biofilms which had a different history of formation. The results summarized in Table 1 indicate that part of the

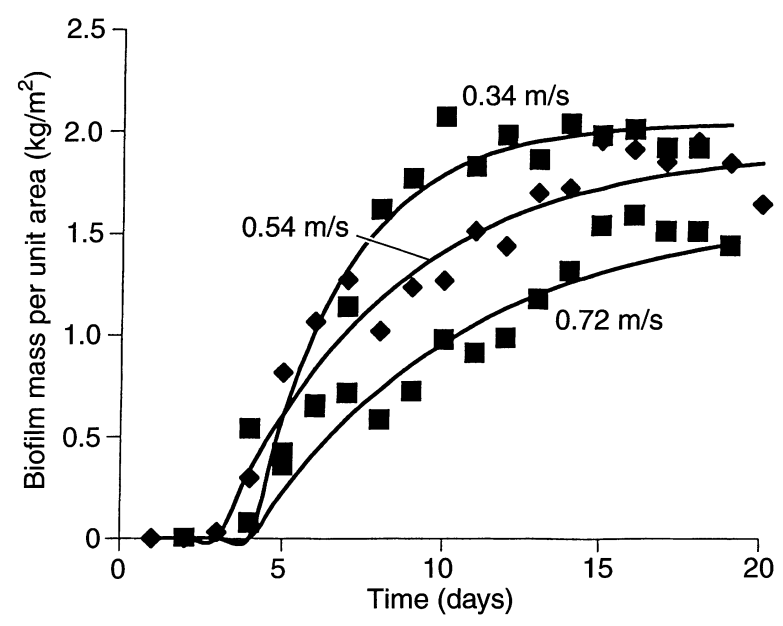

Fig. 2. Illustrative curves of biofilm formation (substrate concentration $=20 \mathrm{mg} / \mathrm{l}$ )
Table 1. Effect of liquid velocity on biofilm density and physical stability

\begin{tabular}{lll}
\hline $\begin{array}{l}\text { Liquid velocity } \\
\text { during biofilm } \\
\text { formation }(\mathrm{m} / \mathrm{s})\end{array}$ & $\begin{array}{l}\text { Dry density of } \\
\text { biofilm }\left(\mathrm{kg} / \mathrm{m}^{3}\right)\end{array}$ & $\begin{array}{l}\text { Fraction of biofilm } \\
\text { removed when the } \\
\text { liquid velocity was } \\
\text { increased to } 1 \mathrm{~m} / \mathrm{s}\end{array}$ \\
\hline 0.35 & 14 & $\begin{array}{c}40 \% \\
0 \%\end{array}$ \\
\hline 0.62 & 28 & $0 \%$ \\
\hline
\end{tabular}

mass of the biofilm formed under lower hydrodynamic forces was washed out by the liquid when the velocity was increased to $1 \mathrm{~m} \mathrm{~s}^{-1}$; conversely, the biological deposit formed under a higher fluid velocity kept stable when the velocity was also increased to $1 \mathrm{~m} \mathrm{~s}^{-1}$.

The cohesiveness (and stability) of a deposit can be considered to be related to its dry density [22]. In the present study, the biofilms subject to stronger hydrodynamic forces contained a higher amount of dry biomass per unit volume of wet biofilm (Table 1). These results confirm the direct relationship between liquid velocity, dry density and stability of the biofilms.

The "dry density" of the biofilm (dry biomass per unit wet volume) has been reported to vary along its depth, from lower values in the zone near the biofilm/liquid interface to higher values near the support $[7,14]$, which suggests that the less dense outer layers will tend to be more easily removed by the hydrodynamic forces than the inner layers. Looking at the results presented in Table 1 in relation to the stability of the biofilms, one can conclude that the outer loose layers occupy a higher fraction of the biofilms when the latter are formed under lower fluid velocities. A simpler way of assessing the biofilm "resistance to detachment" is to compare the values of $1 / b$ obtained by fitting the overall model, Eq. (9), to the biofilm growth curves. In the present study, $1 / b$ increased linearly from $1.5 \times 10^{5} \mathrm{~s}$, for a liquid velocity of $0.34 \mathrm{~m} \mathrm{~s}^{-1}$, to $2.7 \times 10^{5} \mathrm{~s}$, for a liquid velocity of $0.72 \mathrm{~m} \mathrm{~s}^{-1}$.

Therefore, when the goal is to have a firmly attached biomass (such as in waste water biofilm reactors), the formation of biofilms under very low velocities may not be advisable, since it can lead to highly unstable biofilms, with negative direct consequences on the reactor efficiency, in terms of the rate of substrate consumption and of the microbial contamination of the outlet stream. However, although higher velocities will result in thinner and more stable biofilms, there are still doubts on whether the amount of active cells in such biofilms and their biological activity will be lower or higher than in thicker biofilms. The following discussion may shed some light on this subject.

By fitting Eq. (9) to the data in Fig. 2, values of $J_{\mathrm{p}}$ (biofilm production flux) can be obtained. The substrate consumption flux can be calculated from $J_{\mathrm{p}}$ by dividing it by the biomass yield (biomass produced per unit mass of substrate consumed). The latter was measured in suspended cell cultures and its value is $0.93 \mathrm{~kg} \mathrm{~kg}^{-1}$ [21]. Table 2 shows the substrate consumption flux, which is a measure of the biological activity of the biofilm, obtained in various tests. 
Table 2. Substrate consumption by biofilms formed under different liquid velocities

\begin{tabular}{ll}
\hline $\begin{array}{l}\text { Liquid velocity during } \\
\text { biofilm formation }\left(\mathrm{m} \mathrm{s}^{-1}\right)\end{array}$ & $\begin{array}{l}\text { Substrate consumption flux } \\
\times 10^{8}\left(\mathrm{~kg} \text { substrate } \mathrm{m}^{-2} \mathrm{~s}^{-1}\right)\end{array}$ \\
\hline 0.28 & 9.8 \\
0.35 & 8.2 \\
0.46 & 6.7 \\
0.62 & 5.5 \\
\hline
\end{tabular}

These data indicate that the thicker biofilms (those formed in contact with lower liquid velocities) are more active, which means that they contain a greater amount of active cells. This results from the fact that the total biomass of the thicker biofilms is greater than the mass of the thinner ones. Therefore, in turbulent flow, lower velocities favour the formation of thicker, less stable, but more active biofilms.

Another type of tests was performed to obtain information on the fraction of active biomass within the biofilms of Pseudomonas fluorescens. First, the biofilms were grown until they reached steady-state (maximum thickness); then, the substrate (glucose) was suppressed from the flowing liquid. This lead to the detachment of part of the biofilm, due to lack of nutrients, as can be observed in the illustrative curves of Fig. 3.

The fraction of biomass detached from the biofilm after the supression of the substrate depended on the hydrodynamic conditions under which the biofilm was formed, as shown in Table 3.

The biofilms subject to lower velocities appear to be less affected by the lack of substrate than those subject to higher velocities. Although this seems to be in contradiction with Table 1, the two sets of data are not comparable: Table 1 reports a simple physical phenomenon, while Table 3 refers to a metabolical one. In fact, since the substrate is able to penetrate more deeply in thinner biofilms, a higher fraction of their mass will be more dependent on the availability of that substrate. This fraction is thus related to the biofilm mass that detaches from the deposit after the substrate concentration in the liquid is reduced to (practically) zero. Therefore, it can be con-

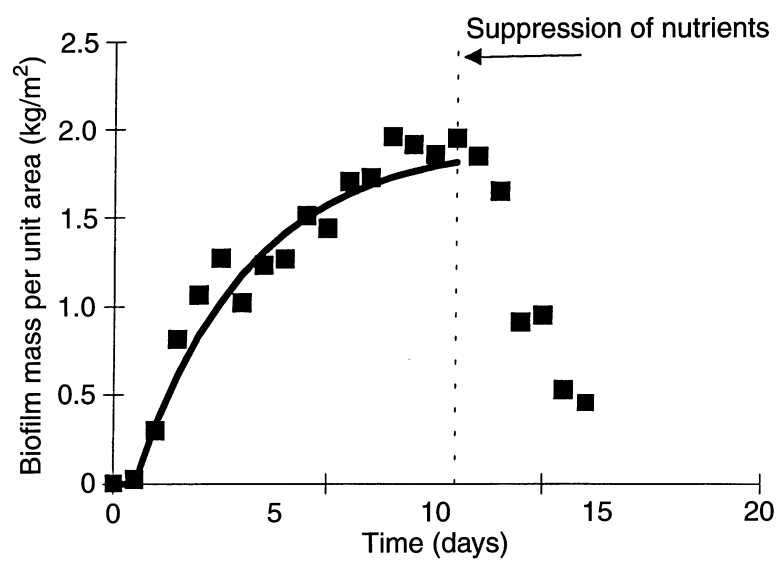

Fig. 3. Effect of suppressing the substrate from the liquid stream
Table 3. Fraction of biofilm mass detached after supression of the substrate

\begin{tabular}{ll}
\hline $\begin{array}{l}\text { Liquid velocity during } \\
\text { biofilm formation } \mathrm{m} \mathrm{s}^{-1} \text { ) }\end{array}$ & $\begin{array}{l}\text { Fraction of biofilm mass detached } \\
\text { after substrate supression }\end{array}$ \\
\hline 0.34 & $21.4 \%$ \\
0.54 & $79.4 \%$ \\
0.72 & $90.7 \%$ \\
\hline
\end{tabular}

cluded from Tables 2 and 3 that lower velocities contribute to the formation of biofilms where greater amounts of substrate are consumed by a smaller percentage of their mass (the upper layer). This means that the density of active cells in the upper zones of these biofilms is probably higher than in thinner biofilms of the same species.

However, since the thicker biofilms are much less stable from a physical standpoint (Table 1), their outer layers are easily removed by the liquid flow, which means that most of their active cells can be washed out from the system when detachment occurs. This has an important practical significance in industrial systems, where unexpected detachment happens much more frequently than in carefully controlled laboratory experiments.

Finally, Fig. 4 confirms that the adhesion of new bacteria coming from the fluid is not relevant for the development and stability of the microbial film, as assumed when deriving the overall model: removing the bacteria from the flowing fluid did not affect the amount of biomass attached to the surface, after the initial surface conditioning period.

A final comment regarding the physical structure of biofilms. Recently, several authors $[9,15]$ have shown pictures obtained with confocal laser scanning microscopy techniques, where biofilms seem to be composed of isolated clusters of cells and biopolymers within a network of liquid channels. This structure is highly heterogeneous and does not adjust to the concept of a more uniform matrix with superimposed active and inactive layers associated to one-dimensional growth and a flat biofilm surface. It is still a matter of controversy whether all biofilms, even those thinner and more compact layers formed under highly turbulent conditions, display such an open structure with so many channels, mainly in the case of "older" biofilms, i.e., with several weeks, as it happens in

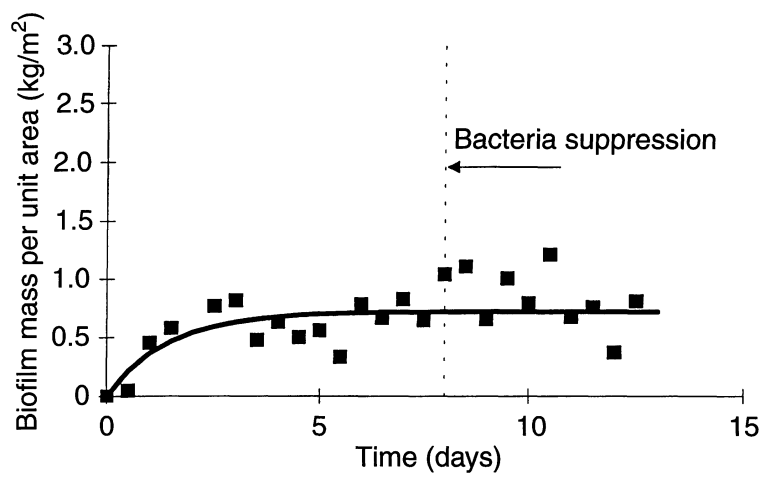

Fig. 4. Effect of suppressing the bacteria from the liquid stream 
heat exchangers and wastewater bioreactors. It should be noted that each "cluster" can also have outer layers with active cells and inner inactive layers where the substrate does not penetrate. Anyhow, the macroscopic results presented in this work are not inconsistent with the traditional image of a layer structured film, and they should be interpreted as average data for the whole biofilm, regardless of local heterogeneities. Although they are not able to shed light upon the detailed structure of the biofilm matrix, these average parameters and properties are certainly most useful for the purpose of defining the design and operating conditions of industrial equipment, be it heat exchangers or bioreactors.

\section{5}

\section{Conclusions}

The experimental study of biofilms formed under turbulent flow conditions and low organic substrate concentration has a particular interest in the case of heat exchanger biofouling. In such a case, due to the very low hydraulic residence time in the equipment, the accumulation and activity of the biofilm cannot be followed by mass balances based on the measurement of inlet and outlet substrate concentrations. Instead, direct monitoring techniques, such as the local measurement of the additional heat transfer resistance introduced by the attached biomass, must be used.

Appropriate mathematical models for this case should include explicit terms describing the development of the biofilm with time, as well as provisions for evaluating the effects of biomass detachment on biofilm growth. A simple "overall model" was established and fitted to the data obtained by continuously monitoring the development of the microbial film from the initial stages. The model yields information about the stability of the biofilm (values of $1 /$ $b$ ) and also about the so-called "biofilm production rate" $\left(J_{\mathrm{p}}\right.$, amount of biomass produced per unit surface area and per unit time) and its substrate consumption capacity.

The physical and biological behaviour of biofilms should be always interpreted taking into account their "past history", i.e., the conditions under which they were formed. In the present work, where turbulent flow and low substrate concentrations were used, higher fluid velocities resulted in thinner biofilms which were more compact and more stable, that is, more resistant to detachment. However, their biological activity was lower than in the thicker biofilms, because the latter have a greater amount of active biomass (concentrated in their upper layers). A balance must be sought between enhancing physical stability (higher velocities) and enhancing biological activity (lower velocities). For instance, in wastewater bioreactors, although thicker biofilms may lead to a higher substrate consumption rate, the time-averaged reactor efficiency may be low because of frequent detachment and wash-out of the active biomass. In heat exchangers, although thinner biofilms introduce a smaller resistance to heat transfer, they can be sometimes more difficult to remove from the surface during the cleaning periods since they are strongly attached and they can also offer a greater resistance to mass transport of biocides through the biological matrix.

\section{References}

1. Bott, T.R.; Pinheiro, M.M.V.P.S.: Biological fouling-velocity and temperature effects, Canad. J. of Chem. Eng. 55 (1977) 473-474

2. Bott, T.R.; Miller, P.C.: Mechanisms of biofilm formation on aluminium tubes, J. Chem. Techn. and Biotech., 33 B (1983) 177-184

3. Bott, T.R.: Fouling of Heat Exchangers. Chap. 12, Elsevier Science B.V. Amsterdam 1995

4. Bryers, J.D.; Characklis, W.G.: Biofilms in water and wastewater treatment, In: Characklis, W.G., Marshall, K.C. (Eds.): Biofilms pp 671-696. N.Y.: John Wiley and Sons 1990

5. Capdeville, B.; Nguyen, K.M.; Rols, J.L.: Biofilm modelling: structural, reactional and diffusional aspects. In: Melo, L.F., Bott, T.R., Fletcher, M. and Capdeville, B. (Eds.) BiofilmsScience and Technology pp 251-276 Dordrecht: Kluwer Academic Publishers, 1992

6. Characklis, W.G.: Biofilm development: a process analysis, Biotech. Bioeng. 23 (1981) 1923-1960

7. Christensen, B.E.; Characklis, W.G.: Physical and chemical properties of biofilms. In: Characklis, W.G., Marshall, K.C. (Eds.): Biofilms pp 93-130. N.Y.: John Wiley and Sons 1990

8. Coelhoso, I.; Rodrigues A.: Modeling of biofilm reactors with consecutive reactions, Bioprocess Engineering 12 (1995) 187192

9. de Beer, D.; Stoodley, P.; Lewandowski, Z.: Liquid flow in heterogeneous biofilms Biotech. Bioeng. 44 (1994) 636-641

10. Harremöes, P.: Biofilm kinetics. In: Mitchel, R. (Ed.): Water Pollution Control Microbiology vol. 2 pp 82-109, N.Y.: John Wiley and Sons, N.Y., 1978

11. Kern, D.; Seaton R.: A theoretical analysis of thermal surface fouling, Brit. Chem. Eng. 4 (1959) 258-262

12. Lewandowski, Z.; Stoodley P.: Flow induced vibrations, drag force and pressure drop in conduits covered with biofilms Wat. Sci Tech. 32 (1995) 11-18

13. Melo, L.F.; Pinheiro, J.D.: Particulate fouling: controlling processes and deposit structure, $8^{\text {th }}$ International Heat Tansfer Conference, paper HX-16, 2781-2786, S. Francisco, 1986

14. Peyton, B.M.: Effects of shear stress and substrate loading rate on Pseudomonas aeruginosa biofilm thickness and density. Wat. Res., 30 (1996) 29-36

15. Stoodley, P.; de Beer, D.; Lewandowski, Z.: Liquid flow in biofilm systems. Appl. Environ. Microb. 60 (1994) 2711-2716

16. Taborek, J.; Aoki, T.; Ritter, R.B.; Palen, J.W.; Knudsen, J.G.: Predictive methods for fouling behaviour. Chem. Eng. Pogr. 68 (1972) 69-78

17. Tavares, C.R.G.; Santana, G.L.Jr.; Capdeville, B.: The effect of air superficial velocity on biofilm accumulation in a threephase fluidized-bed reactor. Wat. Res 29 (1995) 2293-2298

18. van der Kooij, D.; Vrouwenvelder, H.S.; Veenendaal, H.R.: Kinetic aspects of biofilm formation on surfaces exposed to drinking water, Wat. Sci. Techn. 32 (1995) 61-65

19. van Loosdrecht, M.C.M.; Eikelbom, D.; Gjaltema, A.; Mulder, A.; Tijhuis, L.; Heijnen J.J.: Biofilm structures, Wat. Sci. and Techn. 32 (1995) 35-44

20. Vieira, M.J.; Melo, L.F.; Pinheiro, M.M.: Biofilm formation: hydrodynamic effects on internal diffusion and structure. Biofouling 7 (1993) 67-80

21. Vieira, M.J.: Study of the formation of biological films by Pseudomonas fluorescens and of the effects associated to internal mass transfer and incorporation of kaolin particles, $\mathrm{PhD}$ thesis (in portuguese), Univ. Minho, 1995

22. Wanner, O.; Gujer, W.: A multispecies biofilm model. Biotech. Bioeng 28 (1986) 314-328 